\title{
The Influence of Product Diversity on Consumers' Impulsive Purchase in Online Shopping Environment
}

\author{
Yingyi Wu, Haiquan Chen, Hu'an Wang \\ School of Management, Jinan University, Guangzhou, China \\ Email: yingyi_wu@126.com
}

How to cite this paper: $\mathrm{Wu}, \mathrm{Y} . \mathrm{Y} ., \mathrm{Chen}$, H.Q. and Wang, H.A. (2019) The Influence of Product Diversity on Consumers' Impulsive Purchase in Online Shopping Environment. American Journal of Industrial and Business Management, 9, 680-698. https://doi.org/10.4236/ajibm.2019.93046

Received: February 28, 2019

Accepted: March 19, 2019

Published: March 22, 2019

Copyright $\odot 2019$ by author(s) and Scientific Research Publishing Inc. This work is licensed under the Creative Commons Attribution International License (CC BY 4.0).

http://creativecommons.org/licenses/by/4.0/

\begin{abstract}
This paper explores the impact of product diversity on consumers' online impulse purchase intentions in the context of e-commerce development, and finds that product diversity has a significant negative impact on consumers' online impulse buying intentions. Compared with the great product diversity, consumers have higher online impulse buying willingness when they do not have many choices. Further, we found that this effect is regulated by different shopping objects (oneself vs. intimate others). At the same time, information processing fluency plays a mediating role in this effect.
\end{abstract}

\section{Keywords}

Product Diversity, Information Processing Fluency, Online Impulse Purchase Intention, Shopping Objects

\section{Introduction}

With the advent of the "Internet + " and "Big Data" era, consumers' shopping mode is gradually shifting from traditional physical store shopping to online shopping. Online shopping has become an indispensable part of consumer's daily life, and even gradually began to replace the original dominant entity consumption. More businesses and scholars begin to pay attention to online shopping, especially online impulse buying. Due to the convenience of the network, online products are becoming more various, and $50 \%-80 \%$ of online shopping comes from impulse buying. However, in the case of consistent prices and other conditions, will the diversity of products affect consumers' online impulses to purchase the product? At the same time, many people have such experience that when they are browsing on the Internet to buy something for themselves, sud- 
denly they browse a product and feel that the product is very suitable for their family or good friends, in the case of price and quality assurance, they would place an order for their family or friends immediately. In the real business environment, the e-commerce marketing activities are mainly to stimulate consumers to buy for themselves, and every special festival such as Mother's Day, Children's Day and other festivals, online businesses will do a series of targeted promotional and thematic activities to attract customers to buy products or gifts for mothers, children, etc., to stimulate sales of specific products or seasonal products. Therefore, will different shopping objects (buying for themselves, or for intimate others such as family and good friends) have different impulse differences in online shopping? If there are differences, what are the causes of the difference? Many of the above phenomena and problems are subject to further research.

At present, there are abundant studies on consumers' online impulsive buying, but most of them are from the perspectives of cultural differences, remoteness, expected regret, product type, price promotion, online store image, and consumer traits. And few people pay attention to product diversity and whether they purchase for themselves or for intimate others (Hausman, Siekpe, 2009; Parboteeah, 2009) [1] [2]. It is widely believed that the more products available, the more likely consumers are to buy (Broniarczyk, Hoyer \& McAlister, 1998) [3], and most studies generally default to people buy things for themselves. But in actual online shopping, individuals not only buy items for themselves but also for family and friends, intimate others (Dunn, Aknin, Norton, 2008) [4]. At the same time, studies have found that there are more products to choose from, consumers do not buy immediately, but there is a phenomenon of delayed selection (Polman, 2012) [5]. Based on the above situation, this research is mainly from the perspective of product diversity, and then the mechanism of consumers' online impulsive purchase intention is discussed. At the same time, this article also explores whether consumers' impulse purchase intention varies when they buy for themselves or for intimate others. From the perspective of product diversity and shopping objects (oneself-intimate others), this study explores the impact of both on online impulse purchase intentions, the theory of product diversity, online impulse purchases, and self-decision decisions would be enriched, and new research perspectives for online impulse buying are also being provided.

At the same time, in the actual life, the research conclusions of this study also enable online merchants and enterprises to make full use of the research results in marketing and promotion, and the businesses and enterprises could adopt practical product mix and promotion plan for different shopping objects, in order to promote consumers' online impulse buying behavior, and obtain more profits and benefits. Based on the above summary, this article is dedicated to clarifying the following issues:

1) When consumers shop online, they often face different product choices. So, if other factors such as price remain unchanged, will the diversity of products 
affect consumers' willingness to buy online? Will there be any difference in product diversity? If so, what is the difference?

2) Exploring the mediating role of information processing fluency. This article mainly explores the mediating effect of information processing fluency on product diversity and consumers' online impulse buying.

3) Exploring the adjustment role of shopping objects (oneself-intimate others). By manipulating the shopping objects, its influence on the fluency of consumer information processing would be explored, and then in the context of purchasing for oneself or intimate others, the differences of consumers' online impulse buying willingness would also be explored.

\section{Theoretical Framework}

\subsection{Product Diversity and Online Impulse Purchase Intention}

According to classical economics theory, if consumers have more choices, consumers will find more satisfied with the product. In the field of psychology, some scholars believe that the more choices consumers have, the more self-control they need, which will make consumers pay more attention to their inner desires and satisfaction. Traditional marketing believes that the more choices a merchant offers to a customer, the better the effect, because they believe that the higher the diversity of the goods, the more sensitive the consumer needs, the quicker choice (Kahn, Wansink, 2004) [6], from the many choices When judging, I feel more autonomy, and the diversified needs are more satisfied when making choices (Ratner, 2002) [7]. One of the important interests of consumers is that they are free to make choices that satisfy themselves in a wide range of products. The more product options consumers face, the more likely they are to buy the ideal product (Broniarczyk, 1998) [3], the easier it is to buy the product. However, the reality is not always the case. Some scholars have found that when consumers have too many options, it is very difficult to choose the most satisfactory products and purchase them. At this time, consumers are more willing to delay or not choose. At the same time, consumers generate more negative emotions (Schwartz, 1983; Chernev, 2003; Iyengar, 2000) [8] [9] [10], while negative emotions can inhibit consumer buying behavior; at the same time, some scholars find that during the sales process Properly reducing the number of products in the selection set will lead to an increase in performance (Boatwright, Nunes, 2001) [11]. Studies have shown that as the number of alternative products increases, there is a phenomenon of "select overload" (Chernev, 2003; Schwartz, 2004) [9] [12]. "Selecting overload" means that the more choices are offered to consumers, the easier it is for consumers to experience the difficulty of choice, leading to delayed decision making or even no decision making, and reduced consumer satisfaction and more likely to produce regrets (Iyengar, 2000) [10].

Consumers often face different product options when they shop online, ranging from products with low diversity of only two options to products with more than a dozen options. It is also easier to motivate impulse buying behavior in on- 
line shopping situations. When the diversity of products offered online is low, consumers are faced with fewer products to choose from, and it is easier to process product information, and the trade-offs and comparisons are less difficult (Iyengar, Lepper, 2000) [10]. Easy to make choices. At the same time, when it is easier to choose, the satisfaction of choice is higher, which leads to positive emotions, and positive emotions will enhance consumers' willingness to purchase. Since online stores break through the limitations of the time and space of physical store shelves, most online stores tend to offer consumers a richer range of products. When the degree of product diversity is higher, that is, the more products that consumers can choose, the consumers face too much product information, and spend more time and energy on product information processing and trade-off comparison (Iyengar, Lepper, 2000) [10], paying more cognitive efforts, greatly increasing the difficulty for consumers to compare and select the final product (Chernev, 2003) [9], may reduce consumer satisfaction, lead to more regrets (Madhavaram, 2004) [13], thereby reducing the impulses and desires of consumers to buy. On the other hand, the higher the product diversity, the more difficult it is to choose, the more likely it is to trigger consumer negative emotions and reduce the self-confidence of consumer choice (Chernev, 2003) [9]. Negative emotions and low self-confidence also have a certain inhibitory effect on consumers' willingness to buy online impulses (Floh, Madlberger, 2013) [14]. Therefore, this study proposes the hypothesis:

H1: Product diversity has a significant direct impact on consumers' willingness to online impulse purchase intention. Consumers have a higher willingness to purchase online impulses when product diversity is low.

\subsection{Information Processing Fluency}

The online purchase decision refers to the process in which consumers select and purchase satisfactory products from two or more items on the network platform. The essence is that the consumer processes the information of the product and eventually converts it into a process of buying or abandoning the purchase. Information processing fluency refers to the ease of how people feel when processing information (Jacoby, Dallas, 1981) [15]. Products that match people's hobbies and things that match lifestyles, or that are easy to identify and process, are more likely to motivate their preference for products or to enhance the perception of something, and then to streamline products or information. Processing. The influence of fluency on individuals is not only reflected in the cognitive aspect, but also has an effect on the individual's attitude towards and follow-up behavior. In the study of purchasing behavior, the fluency of product information processing will affect the impulse buying behavior, that is, the higher the fluency, the stronger the willingness to purchase. On the one hand, when people's information processing is relatively smooth, there will be a relatively easy and smooth feeling, which will produce a pleasant experience, which will stimulate a more positive mood. Consumers will attribute this more positive 
feeling to the information processing object they face, and will make a simple and emotional treatment of the object, resulting in more positive behavior and a stronger preference for information processing objects. (Schwarz, 2004) [12], it is easier to generate impulsive buying intentions (Strack, 2004) [16]. On the other hand, when individuals feel that the information is easier and smoother, they tend to think that their behavior is "correct", and the behavior associated with the thing or the subsequent behavior tends to increase (Avnet, Higgins, 2006) [17]. When individuals feel that the information they receive is not so easy to understand and that information processing is difficult, they are committed to finding reasons to reduce difficulties, paying more time and energy to think and compare, and making it easier to postpone decisions (Novemsky, Dhar, Schwarz, \& Simonson, 2007) [18].

In this study, consumers need to process information on products offered by online stores when making online purchase decisions. When the degree of product diversity is low, the product information is relatively small, the processing and processing of product information is easier, and the products can be compared relatively quickly (Iyengar, Lepper, 2000) [10], at this time, a relatively high experience will be experienced. Information processing is fluent and produces positive emotions. At this time, consumers tend to attribute this positive emotion to the product itself, and then have a strong preference for the product (Schwarz, 2004) [12], with a stronger impulse to buy (Strack, 2004) [16]. When the degree of product diversity is high, the amount of product information is large, consumers need more processing information, and the difficulty of trade-offs and comparisons increases (Iyengar, Lepper, 2000) [10]. Consumers need to pay more cognitive efforts. (Gourville, Soman, 2005; Greifeneder, Scheibehenne \& Kleber, 2010) [19] [20], which greatly increases the difficulty for consumers to choose the final product (Chernev, 2003) [9], making it easier for consumers to postpone decision making (Novemsky, Dhar, Schwarz, \& Simonson, 2007) [18], impulsive purchase intention is reduced. Therefore, this study proposes the hypothesis:

H2: Information processing fluency mediates between product diversity and online impulse purchase intention.

\subsection{Shopping Object}

When individuals face the exact same buying scenario (decision issues), there are certain decision differences or deviations between buying for themselves (making decisions for themselves) and buying for others (making decisions for others) (Lu, Xie, Xu, 2013) [21]. In theory, if the individual is completely rational, then whether it is for himself or for others to make purchasing decisions, it should be the same, there will be no deviation. However, in reality, it is impossible for people to make decisions that are completely rational. According to Bounded Rationality theory, individuals' own experiences, knowledge, and limitations of the external environment can influence individual decision-making, 
making it impossible for people to make completely rational decisions in decision-making, not to mention the need to transform roles for themselves or others. Make a choice.

This article studies whether to buy for intimate others or to buy for yourself, which is essential for making decisions for themselves or for others. Studies have shown that there are certain differences in the weight of the attributes of things for their own decisions and for others. The study found that consumers are more likely to indulge in hedonic consumption when buying for others, and more inclined to cautious practical consumption when buying for themselves, and the reason for this difference is the change of expected guilt caused by hedonic consumption (Lu, Liu \& Fang, 2016) [21]. Novak think individual when making purchase decisions, you need to consider the psychological state of change, the need of interests and benefits, the main purpose of the purchase products, etc. So they explored the differences between different online purchase behavior [22]. When individuals make decisions for themselves, they will pay more attention to the detailed local features (workplaces, house features, etc.) at the edge of things, and pay more attention to the specific implementation process of the final state of things, preferring simple and easy options. When making decisions for others, they will not consciously pay more attention to the core information characteristics related to the target (such as work pay, etc.), and care about the ultimate state of things. In the shopping situation, individuals are more accustomed to considering the factors affecting the product's multiple angles (such as quality, size, color, and others' evaluation) when purchasing products for themselves. They believe that each factor is equally important and should be equal. Consider, choose the highest score for each factor. When purchasing products for intimate people, they tend to identify an important attribute (such as quality) based on the "others" preference or based on their own understanding of "others", and select the best in this dimension. (Kray, 2000) [23]. There are also differences in the choice of overload between yourself and others. Consistent with previous research, Polman (2010; 2016) [24] [25] found that when individuals make decisions for themselves, there is an option overload effect, which is reversed when making decisions for others. That is, when making decisions for others, the more options you have, the more satisfied you are. A 2008 study found that people feel happier when shopping for others and shopping for others (Dunn, Aknin, \& Norton, 2008) [5], making it easier to buy.

The difference in processing process proposed by Pollai and Kirchler (2012) [26]. Further illustrates the differences in information processing between individuals in their decision-making for themselves and for others. When making decisions for themselves, individuals tend to focus on a variety of information (Laran, 2010) [27], which will take into account multiple factors, give equal weight to all aspects, weigh the comparison, choose the best, and pay more recognition. Knowing to work on information processing (Greifeneder, 2010) [20]. 
When making decisions for others, more attention is paid to an important dimension (Laran, 2010) [27]. The best choice for this dimension is less information processing and less cognitive effort. Based on the above analysis, this study believes that when shopping online, when consumers buy products for themselves, consumers tend to pay attention to a variety of information (Laran, 2010) [27], pay more attention to the edge characteristics of things (Liviatan, 2008) [28], when product diversity When the relevant information changes, the degree of information processing changes, when the product diversity is high, the degree of information processing increases, and more cognitive efforts are required (Greifeneder, 2010) [20], making it easier to postpone decision making (Novemsky, Dhar, Schwarz \&Simonson, 2007) [18], impulse purchase intentions are reduced. At the same time, according to the choice of overload effect, the more choices, the consumers face excessive information processing and trade-off comparison, the information processing fluency is lower, the satisfaction of choice is decreased (Polman, 2012) [29], more willing Delayed selection (Novemsky, Dhar, Schwarz, \& Simonson, 2007) [18], impulsive purchase intentions are reduced. When purchasing products for intimate others, consumers tend to respond to products according to a certain dimension (such as other people's preferences) (Laran, 2010) [27], less product information processing, higher information processing fluency, and easier for consumers to make. Positive decision-making, impulsive purchase will be stronger. At the same time, when shopping for others, individuals will perceive more happiness, which in turn will generate positive emotions, while positive emotions will enhance consumers' online impulse purchase intention. Therefore, this study proposes the following assumptions:

H3: Shopping objects has moderate effect on the impact of product diversity on consumers' online impulse purchase intention. When purchasing products for Intimate Others, There is no significant effect of product diversity on consumers' impulse purchase intention. However, when purchasing products for themselves, product diversity effects negatively on consumers' impulse purchase intention.

\section{Study 1}

Study 1 was conducted to test hypotheses 1 and 2 . We test the impact of product diversity on consumers' online impulse purchase intention, and test the mediating role of information processing fluency.

\subsection{Subjects and Procedure}

The experimental scene of this study was set in the online shopping environment. The young people group was selected as the test sample, where most of them come from universities. The study will focus on consumers mainly consist of students, and have online shopping experience between the ages of 18 and 30. Therefore, the first experiment is going to distribute questionnaires online by sending links, and invite students to participate in it. For the choice of sample, 
We selected 12 college students in Guangzhou who have more than 8 years of rich online shopping experience and have shopping greater than 15 categories for interviews and questionnaires. The most frequently mentioned products were USB, clothes, stationery, digital electronics, shoes, food and daily necessities. In the pre-test, we conducted the screening process of the experimental products, and found that USB is a product for daily use compared with clothing and other products, and the subjects have no greater preference for USB, which is more suitable for the experiment to control other influencing factors for better manipulation. So we chose one popular USB as the experimental object.

The Experiment 1 was a 2 (product diversity: high vs. low) single factor group design. Participants were randomly assigned with two different questionnaires, products with high diversity group and low diversity. The experimental questionnaire consists of four parts, including introduction, experimental scenarios and variable measurement and basic information of the participants. The experimental scenario mainly refers to the impulsive study of Rook \& Fisher (1995) [30], Rook and Fisher using the scenario hypothesis. In order to comply with the thinking habits of Chinese online shopping consumers, this study has made appropriate modifications.

The specific experimental scenario is: You are browsing an online store online and planning to buy a mouse. When browsing this store, you stumbled upon a promotion of an USB in it, and found that the quality of this USB is guaranteed, the design and style are very novel, which is the type you like, and the price is very suitable.

The manipulation of product diversity is mainly reflected by displaying different numbers of product images on the product selection page. After reading the scenario described above, they were asked to choose from the following options (experimental questionnaire): I have a strong desire to have this USB; I have a strong desire to buy this USB; If I do not buy this USB, I will not be satisfied; I am more likely to buy this USB; I really want to get this USB. Finally, the basic information survey of the participants included gender, age, education, monthly expenses, and online shopping frequency.

Referring to the previous research on online impulse purchase, there are many factors influencing consumers' online impulse purchase. This study carried out related treatments during the experiment. First, select the USB with the same gender acceptance as the experimental stimulator, and exclude the influence of gender on the experimental results. The online browsing does not involve the description of the shopping page and the specific product brand, and controls the website design and brand results. Second, in the description of the product does not involve price, promotion, etc., the study will control price factors and the impact of promotion on experimental results; third, the study will carry out basic statistics such as gender, age, shopping frequency. At the same time, the effects of gender, age, shopping frequency, etc. on the experimental results were excluded. 


\subsection{Results}

The experimental samples of Experiment 1 were divided into 2 groups, 40 samples in each group, a total of 80 questionnaires were distributed, and 72 samples were actually recovered. There are 69 valid questionnaires in total after removing the failed questionnaires. The effective rate of the questionnaire was $95.83 \%$. The Cronbach's alpha of online impulse purchase intention is $0.93\left(\alpha_{\mathrm{OIPI}}=0.93\right)$. The Cronbach's alpha of product diversity is $0.81\left(\alpha_{\text {product diversity }}=0.81\right)$. AND the Cronbach's alpha of the information processing fluency is 0.85 ( $\alpha_{\text {information processing }}$ fluency $=0.85)$.

Manipulation Check. A one-way ANOVA showed that the product diversity when the product option was 10 was significantly higher than the product option of $4\left(\mathrm{M}_{\text {high product diversity }}=3.77, \mathrm{SD}=1.09, \mathrm{M}_{\text {low product diversity }}=4.99, \mathrm{SD}=0.97, \mathrm{~F}\right.$ $(1,68)=23.68, \mathrm{p}<0.05)$. Therefore, product diversity is effective in the manipulation of online impulse purchase intention.

Hypothesis Check. The impact of product diversity on online impulse purchase intention. A one-way ANOVA, product diversity as an independent variable and consumers' online impulse purchase intention as a dependent variable, showed that product diversity on consumers' online impulse purchase intention is significant $(\mathrm{F}(1,68)=35.65, \mathrm{p}<0.05)$, Consumers with low product diversity have more willingness to impulses purchase than high product diversity group $\left(\mathrm{M}_{\text {low product diversity }}=4.61, \mathrm{SD}=1.26 ; \mathrm{M}_{\text {high product diversity }}=2.85, \mathrm{SD}=1.18\right)$, so it is assumed that $\mathrm{H} 1$ is verified showing in Figure 1.

First, we tested the significance of $c$ in Equation (1) $(\beta=-0.59, \mathrm{t}(\mathrm{c})=-5.97, \mathrm{p}$ $<0.01)$. Second, We tested the significance of a in Equation (2) $(\beta=-0.52, \mathrm{t}(\mathrm{a})=$ $-4.92, \mathrm{p}<0.01)$, indicating that the independent variable has a significant influence on the mediator variable; Third, We tested the significance of $b$ in Equation (3) $(\beta=0.52, \mathrm{t}(\mathrm{b})=5.30, \mathrm{p}<0.01)$, indicating that the fluency of information processing has a significant mediating effect on product diversity on consumers' online impulses purchase intention. Then we test $c$ of the equation $(\beta=-0.32$, $\left.\mathrm{t}\left(\mathrm{c}^{\prime}\right)=-3.34, \mathrm{p}<0.05\right)$, indicating that the complete mediating effect of information processing fluency is not established, so there is a partial mediating effect. Using Bootstrap analysis in the $95 \%$ confidence interval, the results showed that the confidence interval of the mediation of information processing fluency $(\mathrm{LLCI}=-1.2537, \mathrm{ULCI}=-0.4507)$ does not contain 0 , which shows that information processing fluency has played a mediating role in product diversity and consumer online impulse purchase intention. So hypothesis $\mathrm{H} 2$ has been validated.

Discussion. Providing support for hypotheses 1 and 2, study 1 demonstrated that when product diversity is low, consumers' online impulse purchase intention is higher than that of product diversity is high; information processing fluency has played a mediating role in product diversity and consumer online impulse purchase intention. 


\section{Online Impulse Purchase Intention}

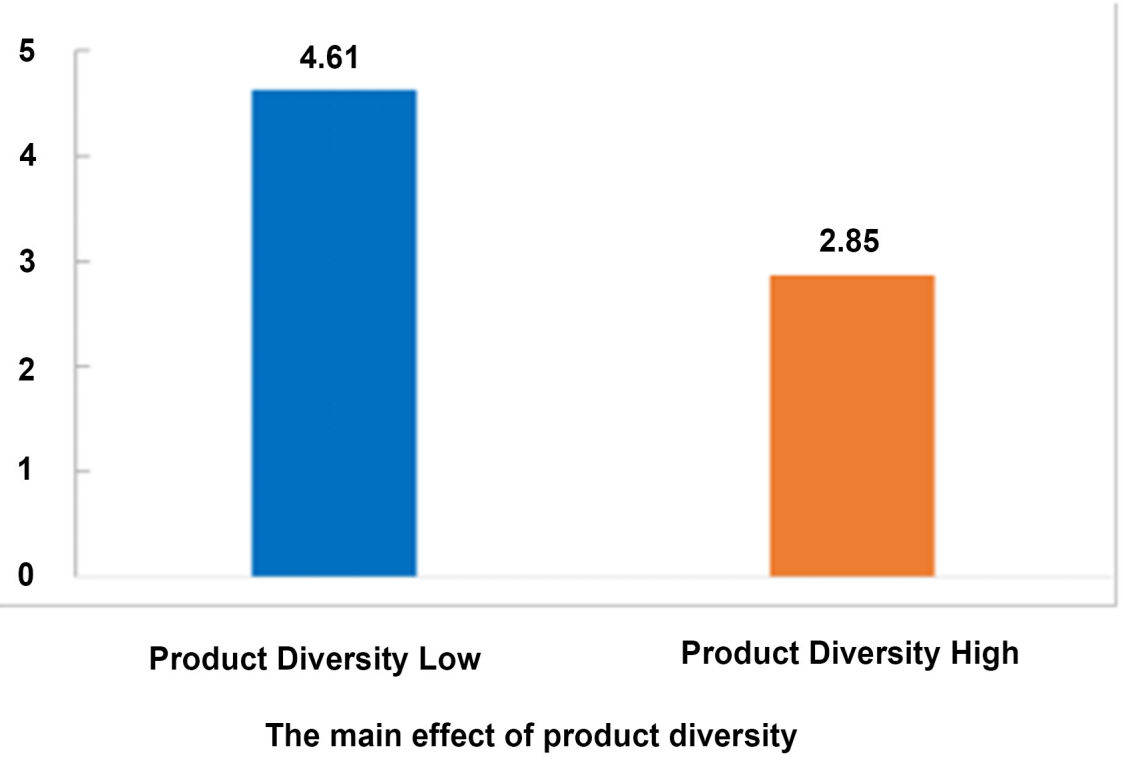

Figure 1. Study 1 results.

\section{Study 2}

Study 2 was conducted to test hypotheses 1,2 and 3. We test the impact of product diversity on consumers' online impulse purchase intention, and test the mediating role of information processing fluency. We also examined the moderating role of shopping objects.

\subsection{Subjects and Procedure}

The experimental scene of this study was set in the online shopping environment. The young people group was selected as the test sample, where most of them come from universities. The study will focus on consumers mainly consist of students, and have online shopping experience between the ages of 18 and 30. Experiment 2 was conducted in the laboratory. We explained the purpose of the experiment and some considerations to the participants. The experimental results will be used for academic research. Four questionnaires were randomly distributed to the participants. For the choice of sample, we interviewed 12 university students in Guangzhou, where the most frequently mentioned products were clothes, stationery, digital electronics, shoes, food and daily necessities, so we chose pens as the experimental object.

The Experiment 2 design is a 2 (product diversity: high vs. low) $\times 2$ (shopping Objects: Oneself vs. Intimate Others). Participants were randomly assigned with 4 different questionnaires, products with high diversity group and low diversity. The experimental questionnaire consists of four parts, including introduction, experimental scenarios and variable measurement and basic information of the 
participants. The experimental scenario mainly refers to the impulsive study of Rook \& Fisher (1995) [29], Rook and Fisher used the scenario hypothesis. In order to comply with the thinking habits of Chinese online shopping consumers, this study has made appropriate modifications. The specific experimental scenario is:

Recently, you/your good friend Julia is about to have a birthday, and you plan to buy a $\mathrm{CD}$ online as a birthday gift for yourself/her. However, you accidentally found a pen while browsing the web. You find that the quality of this pen is very good. Its style belongs to your friends' favorite style, and the price is very suitable. You can accept its price. At the same time, You/You remembered Julia have been paying attention to the brand and like its classic series.

The manipulation of product diversity is mainly reflected by displaying different numbers of product images on the product selection page. After reading the scenario described above, they were asked to choose from the following options: I have a strong desire to have this pen; I have a strong desire to buy this pen; If I do not buy this pen, I will not be satisfied; I am more likely to buy this pen; I really want to get this pen. Finally, the basic information survey of the participants included gender, age, education, monthly expenses, and online shopping frequency.

Referring to the previous research on online impulse purchase, there are many factors influencing consumers' online impulse purchase. This study carried out related treatments during the experiment. First, select the pen with the same gender acceptance as the experimental stimulator, and exclude the influence of gender on the experimental results, We only indicated that the identity or relationship between them is "self or intimate others". The online browsing does not involve the description of the shopping page and the specific product brand, and controls the website design and brand results. Second, in the description of the product does not involve price, promotion, etc., The study will control price factors and the impact of promotion on experimental results; third, the study will carry out basic statistics such as gender, age, shopping frequency. At the same time, the effects of gender, age, shopping frequency, etc. on the experimental results were excluded.

\subsection{Results}

The experimental samples of Experiment 2 were divided into 4 groups, 45 samples in each group, a total of 180 questionnaires were distributed, and 178 samples were actually recovered. There are 161 valid questionnaires in total after removing the failed questionnaires. The effective rate of the questionnaire was $90.45 \%$. The Cronbach's alpha of online impulse purchase intention is 0.91 ( $\alpha$ OIPI $=0.91)$. The Cronbach's alpha of product diversity is 0.84 ( $\alpha$ product diversity $=0.84)$. And the Cronbach's alpha of the information processing fluency is 0.80 ( $\alpha$ information processing fluency $=0.80$ ).

Manipulation Check A ANOVA showed that the product diversity when the 
product option was 10 was significantly higher than the product option of 4 (M high product diversity $=3.11, \mathrm{SD}=1.77, \mathrm{M}$ low product diversity $=5.79, \mathrm{SD}=$ $1.07, \mathrm{~F}(1,68)=24.63, \mathrm{p}<0.05)$. Therefore, product diversity is effective in the manipulation of online impulse purchase intention.

Hypothesis Check. The impact of product diversity on online impulse purchase intention. An ANOVA, product diversity as an independent variable and consumers' online impulse purchase intention as a dependent variable, showed that product diversity on consumers' online impulse purchase intention is significant $(\mathrm{F}=34.19, \mathrm{df}=160, \mathrm{p}<0.05)$, Consumers with low product diversity have more willingness to impulses purchase than high product diversity group $\left(\mathrm{M}_{\text {low product diversity }}=4.74, \mathrm{SD}=0.56 ; \mathrm{M}_{\text {high product diversity }}=3.94, \mathrm{SD}=1.09\right)$, so it is assumed that $\mathrm{H} 1$ is verified.

Mediation Analysis for information processing fluency. In order to test the mediating effect of information processing fluency, we draw on the mediation effect test procedures and methods proposed by Wen $(2004 ; 2006)$ [31] [32]. The independent variable is product diversity $(X)$, the dependent variable is the consumer's online impulse purchase intention $(Y)$, and the mediator variable is information processing fluency $(M)$. The following equation is constructed to test:

$$
\begin{gathered}
Y=c X+e 1 \\
M=a X+e 2 \\
Y=c^{\prime} X+b M+e 3
\end{gathered}
$$

First, we tested the significance of $c$ in Equation (1) $(\beta=-0.80, \mathrm{t}(\mathrm{c})=-5.85, \mathrm{p}$ $<0.01)$. Second, we tested the significance of a in Equation $(2) .(\beta=-0.83, \mathrm{t}(\mathrm{a})=$ $-5.45, \mathrm{p}<0.01)$, indicating that the independent variable has a significant influence on the mediator variable; Third, We tested the significance of $b$ in Equation (3) $(\beta=0.74, \mathrm{t}(\mathrm{b})=18.41, \mathrm{p}<0.01)$, indicating that the fluency of information processing has a significant mediating effect on product diversity on consumers' online impulses purchase intention. Then we test $c$ of the equation $(\beta=\mathrm{i}-0.18$, $\left.\mathrm{t}\left(\mathrm{c}^{\prime}\right)=-2.19, \mathrm{p}<0.05\right)$, indicating that the complete mediating effect of information processing fluency is not established, so there is a partial mediating effect. Using Bootstrap analysis in the $95 \%$ confidence interval, the results showed that the confidence interval of the mediation of information processing fluency $(\mathrm{LLCI}=-0.8378, \mathrm{ULCI}=-0.3901)$ does not contain 0 , which shows that information processing Fluency has played a mediating role in product diversity and consumer online impulse purchase intention. So hypothesis $\mathrm{H} 2$ has been validated.

Shopping Objects (Oneself vs. Intimate Others). In order to test the role of shopping objects role, the general linearity is used for analysis. Taking consumers' online impulse purchase intention as a dependent variable, product diversity (high product diversity $=2$, low product diversity $=1$ ) and shopping objects (intimate others $=2$, self $=1$ ) were analyzed as independent variables. The results of the analysis were consistent with expectations, and the interaction between product diversity and the shopping object (self-intimate) was significant (F (1, 
$157)=155.47, \mathrm{p}<0.001)$. In addition, product diversity also had a significant impact on consumers' willingness to purchase online impulses $(F(1,157)=$ $109.85, \mathrm{p}<0.001)$. Because the interaction between product diversity and shopping objects (oneself-intimate others) is significant, we further carry out simple effect analysis. When purchasing products for intimate others, there is no significant difference in the impact of product diversity on consumers' online impulse purchase intention $\left(\mathrm{M}_{\text {high product diversity }}=4.92, \mathrm{M}_{\text {low product diversity }}=4.76, \mathrm{~F}<1\right)$. When purchasing products for themselves, the consumer have more willingness to purchase $\left(\mathrm{M}_{\text {low product diversity }}=4.72\right)$ is significantly higher than the consumer's impulsive purchase intention when the product diversity is high $\left(\mathrm{M}_{\text {high product diversity }}\right.$ $=2.91), \mathrm{F}=122.94, \mathrm{p}<0.001)$. Therefore, hypothesis $\mathrm{H} 3$ is verified.

Discussion. In Experiment 2, we verified hypothesis1, 2 and 3. Shopping objects (oneself-intimate others) play a moderating role in the impact of product diversity on consumers' online impulse purchase intention. Specifically, when purchasing for itself, the diversity of products adversely affects the fluency of information processing of consumers, which in turn adversely affects consumers' willingness to purchase online; and when purchasing for intimate others, there is no significant difference in the impact of consumer online impulse purchase intention.

\section{General Discussion}

\subsection{Conclusions or Findings}

This study focuses on the issue of "the impact of product diversity on consumers' online impulse purchase intention in a network context". The results show that on the product selection page, consumers have a stronger online impulse purchase intention when the product diversity degree is lower, and the fluency of information processing plays a mediating role. Shopping objects (oneself vs. intimate others) regulate the impact of product diversity on online impulse purchase intention. When consumers buy products for themselves, the diversity of products has a significant negative impact on consumers' intention of online impulse purchase: the higher the degree of product diversity, the lower intention of online impulse purchase. When consumers buy for intimate others, the consumers' online impulse purchase intention is higher, and the degree of product diversity has no significant impact on the consumers' intention of online impulse purchase.

In the context of online shopping, when consumers face diversified products on the product selection page, the more the products are diversified, the more choices that customers are facing. In this situation, customers tend to be delayed to make choices, and therefore they are less likely to be impulsive. When consumers face products with a high degree of diversity, the difficulty of processing product information and comparing the choice of the final product will increase (Iyengar \& Lepper, 2000; Chernev, 2003) [9] [10]. Under those circumstances, consumers prefer fewer choices out there; so if there are more choices, the inten- 
tion of impulsive is lower. For online suppliers, it is not wise to blindly provide consumers with a variety of product options without any careful thinking. The number of products has already large enough to capture the needs of consumers. The thing is whether the consumers' needs are captured. If the diversity level of products provided is low, the differences among each product tend to be large and therefore consumers could compare the products relatively easily when they are processing the information, and the products can be weighed relatively quickly. Consumers tend to attribute this positive experience to the products they are buying, therefore their preference of buying these products will strongly increase, and then they will make decision quickly and submit the order immediately. When consumers face a high diversity of products, the products are highly similar with each other, and there is a more need to process the information. Consumers need to pay more cognitive efforts to make the final choice on products (Iyengar, Lepper, 2000; Chernev, 2006) [9] [10]. They are more likely to give up purchasing, that is, the consumers' online impulse purchase intention would reduce. When buying products for themselves, consumers are more inclined to consider the factors of multiple dimensions, and weight each factor equally, thus the consumers will pay more attention to the secondary features of things (Liviatan, 2008) [26], to make a better decision after comparing multiple factors.

Therefore, as the level of product diversity increases, the increasing information of products makes consumers spend more time and effort processing and analyzing product information, thus it will consume consumers large amount of cognitive resources (Gourville, Soman, 2005; Greifeneder, 2010) [19] [20], and the fluency of information processing will be reduced, and it is easier to postpone decision making (Novemsky, Dhar, Schwarz, \& Simonson, 2007) [18], and then reduce the impulse to purchase.

When purchasing products for intimate relationship, consumers tend to choose the most important dimension from a variety of dimensions based on their understanding of intimate others (Kray, 1999) [33], select the Best-performing product in every dimension, and integrate product information. The information processing is relatively smooth, and it is easier to make positive purchasing decisions. At the same time, when consumers are purchasing for intimate others, as the number of choices of the products increases, the shopping satisfaction will increase (Polman, 2012) [6]. The generating positive emotions will enhance consumer online impulse purchase intentions. Therefore, when consumers purchase for intimate others, the consumers' willingness to purchase online impulses is higher, and the level of product diversity has no significant impact on the consumers' willingness to purchase online impulses.

\subsection{Contributions}

At present, the research of product diversity focuses on product line and product mix strategies, as well as a series of impacts such as impacts of product diversity 
on consumer post-purchase evaluation, brand perception and choice; however, there are few literature reviews put attention on the online context and impulsive purchase intentions. Therefore, based on the perspective of consumer behavior research, this paper introduces the product diversity into the field of impulse purchase, to enrich a further research of diversity. Previous studies have shown that the more diverse the products a consumer faces, the greater the probability that consumers will find a product that meets their preferences; and the more product options consumers face, they can buy more ideal products. (Broniarczyk, 1998) [4], because it is easier to make a purchasing choice. However, in this study, we not only extend the purchase scenario to the online context, but also got an opposite conclusion on a certain selection page of the product, the higher the level of product diversity, the lower the consumer's willingness to purchase online impulses. Most scholars often use the online impulse purchase by the default that they image the experimental object is themselves. Fewer scholars pay attention to the difference between buying products for themselves and purchasing for others. There are even few to distinguish experimental objects differences in the study of impulsive purchases. In actual online shopping, nowadays many online merchants will introduce a series of new products for a specific festival, when consumers will buy products for their family or friends, that is, intimate others. This study combines online shopping theory and practice to clearly define and distinguish others in the study, and determines the actual research scope for intimate others to purchase. Besides, buying for yourself (making decisions for yourself) or for intimate others (making decisions for others), most people focus on money distribution and risk decision-making. There are not many discussions in the field of consumer purchase, especially few on the online impulse purchase research. Therefore, this article, based on the actual facts will introduce the focus on the purchase for oneself or intimate others into the field of online impulsive purchase.

The research conclusions of this paper also have certain enlightenment for e-commerce practice, mainly for the network stores to carry out network marketing. First of all, in online shopping, on the specific selection page of products, the degree of product diversity has a significant impact on consumers' willingness to purchase. With the rapid development of e-commerce, a wide variety of online products have brought certain disadvantages. In the product selection page, excessive product selection may result in a decrease in satisfaction and the willingness to purchase. In this case, a large number of product option settings not only failed to stimulate consumption, but inhibited the impulse purchase behavior of online consumers. Therefore, the online store should set up multiple categories of products in the store, attract consumers to enter the store page to browse, and seize the needs of consumers; on the specific selection page of the goods, consumers need to make choices and make purchasing decisions. It is not appropriate to set too many product options, instead of providing relatively few products, which cause that consumers distinguish quickly the differences among 
the various options, make purchasing decisions quickly, promote product sales and the profitability of the business. Second, E-commerce can set a relatively small number of product options on the specific product selection page to reduce the difficulty of consumer information processing. E-commerce may also highlight the specific product options while setting reasonable options. The lower the similarity among specific product options, the more easily consumers process and process information; the smoother the information processing, the easier for customers to find the best products, and the faster the purchase decision they make, the intention of impulsive the purchase will be higher. Third, based on the analysis of the experimental data in this article, we found that consumers will see significant differences when they buy for themselves and for intimate others. For online marketers or online merchants, they should grasp whether the consumers buy for themselves or for the intimate others (such as family members, good friends, etc.) to target promotion activities. Promote more consumers to impulsive consumption for intimate others, so as to achieve the purpose of increasing product sales.

\subsection{Limitations and Further Research}

The limitations of this study are as following: First, the limitations of the experimental method. Regarding the choice of experimental products, this article was based on a small-scale number of interviews before the experiment. using the relatively familiar products of the consumer to conduct experiments, although the products of the two experiments have Different, but did not classify the products on the Internet, the three products cannot fully represent all the products on the Internet, so there is still some imprecise. This paper mainly studies the impact of product diversity on consumers' online purchase impulse intention, and does not directly study consumer purchasing decision-making behavior. At the same time, there are many reasons for consumers' online purchase factors, and the influencing factors are diverse. This study cannot consider all existing and unknown influencing factors, and has certain limitations.

In the future, products can be classified according to the characteristics of online products, such as search products vs. experience products, to explore whether online impulse purchases of different product types are affected by product diversity. Second, the network environment is not as static as the offline offline shopping environment, and it has more uncertainty. Therefore, the factors that affect consumers' online shopping are very numerous and complex. In the experimental manipulation, this paper only uses the imagination of the consumer to complete the virtual online shopping. There may be different perception errors than the actual shopping. The collected data may also have some deviation. In the future research, We can simulate the simulation scenario on the Internet or cooperate with the real-life shopping website to collect the real purchase data of the consumers in the background, and start from the real big data to study the impulse purchase of product diversity for consumers. 


\section{Conflicts of Interest}

The authors declare no conflicts of interest regarding the publication of this paper.

\section{References}

[1] Hausman, A.V. and Siekpe, J.S. (2009) The Effect of Web Interface Features on Consumer Online Purchase Intentions. Journal of Business Research, 62, 5-13. https://doi.org/10.1016/j.jbusres.2008.01.018

[2] Parboteeah, D.V., Valacich, J.S. and Wells, J.D. (2009) The Influence of Website Characteristics on a Consumer's Urge to Buy Impulsively. Information Systems Research, 20, 60-78. https://doi.org/10.1287/isre.1070.0157

[3] Broniarczyk, S.M., Hoyer, W.D. and Mcalister, L. (1998) Consumers' Perceptions of the Assortment Offered in a Grocery Category: The Impact of Item Reduction. Journal of Marketing Research, 35, 166-176.

[4] Dunn, E.W., Aknin, L.B. and Norton, M.I. (2008) Spending Money on Others Promotes Happiness. Science, 319, 1687-1688. https://doi.org/10.1126/science.1150952

[5] Polman, E. (2012) Effects of Self-Other Decision Making on Regulatory Focus and Choice Overload. Journal of Personality and Social Psychology, 102, 980-993. https://doi.org/10.1037/a0026966

[6] Kahn, B.E. and Wansink, B. (2004) The Influence of Assortment Structure on Perceived Variety and Consumption Quantities. Journal of Consumer Research, 30, 519-533. https://doi.org/10.1086/380286

[7] Ratner, R.K. and Kahn, B.E. (2002) The Impact of Private versus Public Consumption on Variety-Seeking Behavior. Journal of Consumer Research, 29, 246-257. https://doi.org/10.1086/341574

[8] Norbert, S. and Clore, G.G. (1983) Mood, Misattribution, and Judgment and Decision Making. Journal of Consumer Psychology, 14, 332-348.

[9] Chernev, A. (2003) Product Assortment and Individual Decision Processes. Journal of Personality and Social Psychology, 85, 151-162. https://doi.org/10.1037/0022-3514.85.1.151

[10] Iyengar, S.S. and Lepper, M.R. (2000) When Choice Is Demotivating: Can One Desire Too Much of a Good Thing? Journal of Personality \& Social Psychology, 79, 995-1006. https://doi.org/10.1037/0022-3514.79.6.995

[11] Boatwright, P. and Nunes, J.C. (2001) Reducing Assortment: An Attribute-Based Approach. Journal of Marketing, 65, 50-63. https://doi.org/10.1509/jmkg.65.3.50.18330

[12] Barry, S. (2004) The Paradox of Choice. Why More Is Less. Harper Collins Publishers Inc., New York.

[13] Madhavaram, S.R. and Laverie, D.A. (2004) Exploring Impulse Purchasing on the Internet. Advances in Consumer Research, 31, 59-66.

[14] Floh, A. and Madlberger, M. (2013) The Role of Atmospheric Cues in Online Impulse-Buying Behavior. Electronic Commerce Research \& Applications, 12, 425-439. https://doi.org/10.1016/j.elerap.2013.06.001

[15] Jacoby, L.L. and Dallas, M. (1981) On the Relationship between Autobiographical Memory and Perceptual Learning. Journal of Experimental Psychology General, 110, 306-340. https://doi.org/10.1037/0096-3445.110.3.306 
[16] Strack, F. and Deutsch, R. (2004) Reflective and Impulsive Determinants of Social Behavior. Personality and Social Psychology Review, 16, 220-247. https://doi.org/10.1207/s15327957pspr0803_1

[17] Avnet, T. and Higgins, E.T. (2006) How Regulatory Fit Affects Value in Consumer Choices and Opinions. Journal of Marketing Research, 43, 1-10. https://doi.org/10.1509/jmkr.43.1.1

[18] Novemsky, N. and Schwarz, N. (2007) Preference Fluency in Consumer Choice. Journal of Marketing Research, 44, 374-356. https://doi.org/10.1509/jmkr.44.3.347

[19] Gourville, J.T. and Soman, D. (2005) Overchoice and Assortment Type: When and Why Variety Backfires. Marketing Science, 24, 382-395. https://doi.org/10.1287/mksc.1040.0109

[20] Greifeneder, R., Scheibehenne, B. and Kleber, N. (2010) Less May Be More When Choosing Is Difficult: Choice Complexity and Too Much Choice. Acta Psychologica, 133, 45-50. https://doi.org/10.1016/j.actpsy.2009.08.005

[21] Lu, J., Liu, Z. and Fang, Z. (2016) Hedonic Products for You, Utilitarian Products for Me. Judgment \& Decision Making, 11, 332-341.

[22] Novak, T.P., Hoffman, D.L. and Duhachek, A. (2003) The Influence of Goal-Directed and Experiential Activities on Online Flow Experiences. Journal of Consumer Psychology, 13, 3-16. https://doi.org/10.1207/153276603768344744

[23] Kray, L.J. (2000) Contingent Weighting in Self-Other Decision Making. Organizational Behavior \& Human Decision Processes, 83, 82-106. https://doi.org/10.1006/obhd.2000.2903

[24] Polman, E. (2010) Information Distortion in Self-Other Decision Making. Journal of Experimental Social Psychology, 46, 432-435. https://doi.org/10.1016/j.jesp.2009.11.003

[25] Polman, E. and Vohs, K.D. (2016) Decision Fatigue, Choosing for Others, and Self-Construal. Social Psychological \& Personality Science, 7, 471-478. https://doi.org/10.1177/1948550616639648

[26] Pollai, M. and Kirchler, E. (2012) Differences in Risk-Defusing Behavior in Deciding for Oneself versus Deciding for Other People. Acta Psychologica, 139, 239-243. https://doi.org/10.1016/j.actpsy.2011.09.013

[27] Laran, J. (2010) Goal Management in Sequential Choices: Consumer Choices for Others Are More Indulgent than Personal Choices. Journal of Consumer Research, 37, 304-314. https://doi.org/10.1086/652193

[28] Liviatan, I., Trope, Y. and Liberman, N. (2008) Interpersonal Similarity as a Social Distance Dimension: Implications for Perception of Others' Actions. Journal of $E_{X^{-}}$ perimental Social Psychology, 44, 1256-1269. https://doi.org/10.1016/j.jesp.2008.04.007

[29] Polman, E. (2012) Self-Other Decision Making and Loss Aversion. Organizational Behavior \& Human Decision Processes, 119, 141-150. https://doi.org/10.1016/j.obhdp.2012.06.005

[30] Rook, D.W. and Fisher, R.J. (1995) Normative Influences on Impulsive Buying Behavior. Journal of Consumer Research, 22, 305-313. https://doi.org/10.1086/209452

[31] Wen, Z.L., Zhang, L. and Hou, J.T. (2006) Intermediary Regulatory Variables and Regulated Mediator Variables. Journal of Psychology, 38, 448-452.

[32] Wen, Z.L., Zhang, L. and Hou, J.T. (2004) The Mediation Effect Test Procedure and Its Application. Journal of Psychology, 36, 614-620. 
[33] Kray, L. and Gonzalez, R. (1999) Differential Weighting in Choice versus Advice: I'll Do This, You Do That. Journal of Behavioral Decision Making, 12, 207-218. https://doi.org/10.1002/(SICI)1099-0771(199909)12:3<207::AID-BDM322>3.0.CO;2 $\underline{-\mathrm{P}}$ 